\title{
Analysis of Issues in Dentistry Using Topic Modeling
}

\author{
Kyung-Hui Moon \\ Department of Dental Hygiene, Jinju Health College, Jinju, Korea
}

Objective: This study collected articles released by BIGKinds (www.bigkinds.or.kr), which is a big data service made available by the Korea Press Foundation, by applying search keywords including "corona" and "dentistry" from January 6, 2020 to June 30, 2021.

Methods: Data extracted using NetMiner (Cyram Inc., Seongnam, Korea) was subject to a refining process to extract only keywords with a Term Frequency-Inverse Document Frequency coefficient of 0.5 or higher and Latent Dirichlet Allocation topic modeling was performed to derive the topics.

Results: Of the 5 derived topics, the topic accounting for the greatest portion was "vaccination", followed by "dental health care", "medical industry", "time of confusion during the COVID-19 pandemic", and "changes in daily life during the COVID-19 pandemic".

Conclusion: The biggest issue in the dental sector in 2020 and the first half of 2021 due to the spread of COVID-19 were found to be "vaccination", "dental health care", "medical industry", "time of confusion during the COVID-19 pandemic", and "changes in daily life during the COVID-19 pandemic". In the future, research should be conducted to better understand changes in the dental sector and plans for systematically resolving such issues.

Keywords: dentistry, COVID-19, news articles, topic modeling

\section{Introduction}

COVID-19 is a respiratory syndrome caused by SARS-CoV-2 infections, and its reported transmission path is currently known to be through droplets and contact [1]. COVID-19 is known to have spread in South Korea initially through a Chinese person who visited South Korea on January 20, 2020 and was the first confirmed person infected. On January 27,

Corresponding author Kyung-Hui Moon

E-mail: next77_kr@naver.com

(iD) https://orcid.org/0000-0002-4584-4237

Received September 7, 2021, Revised September 17, 2021, Accepted September 22, 2021
2020 the COVID-19 warning level was raised from "Caution (domestic inflow)" to "Warning (limited domestic spread)", and the Central Accident Control Headquarters was installed. The number of daily and accumulated confirmed cases is repeatedly fluctuating, and the level of social distancing requirements are also repeatedly being adjusted and extended [2].

The World Health Organization (WHO) declared a public health emergency of international concern and in March escalated this to the declaration of a state of global pandemic. As the COVID-19 pandemic became prolonged, people gained a more heightened awareness of health risks compared to the pre-pandemic period. This has brought many changes not only in daily lives, but also in the medical environment. Social distancing and mask wearing are being emphasized to stop the spread of COVID-19, while other measures are also being ap-

Copyright (C) 2021. Korean Academy of Preventive Dentistry. All rights reserved.

This is an Open Access article distributed under the terms of the Creative Commons Attribution Non-Commercial License (http://creativecommons.org/licenses/ by-nc/4.0) which permits unrestricted non-commercial use, distribution, and reproduction in any medium, provided the original work is properly cited. 
plied, such as ventilating indoor environments, purifying air, washing hands, covering one's mouth when coughing or sneezing, covering buttons with anti-virus materials such as copper, and self-quarantining of persons exposed to the virus, etc. [3].

The development of text mining technologies advanced through information communication technologies that make text data analysis possible. Text mining handles text data, which are nonlinear data, and therefore have incompleteness in the pre-treatment process, but compared to the content analysis method, it can reduce human labor while enhancing the objectivity of research [4]. Topic modeling is a method that estimates all topics from a group of documents based on words that appear in each document and automatically extracts the topics corresponding to individual documents and the words that make up each topic based on probability distribution [5]. Therefore, the advantage of topic modeling is that it identifies patterns where words are frequently associated to appear to deduce consistent topics [6]. Latent Dirichlet Allocation (LDA) was later develop as a generative probabilistic model that judges what topics exist in each document that represents the current topic modeling method using probability [5].

Accordingly, this study will identify media data of various issues and articles, etc., relating to COVID-19 through the big data analysis method. This study intends to set key search words such as 'corona' and 'dentistry' to collect news articles in BIGKinds (www.bigkinds.or.kr), a big data service, and then perform topic modeling, which is a text mining technique, to find the social issues in the dental sector following the spread of COVID-19 to derive future implications.

\section{Materials and Methods}

\section{Subjects}

This study collected news articles from BIGKinds. For this study, the key search words were set as 'corona' and 'dentistry' to collect news articles. The search period was from January 6 , 2020 [7], the date on which the first article on COVID-19 was released on BIGKinds, up to June 30, 2021, and a total of 688 cases were analyzed.

\section{Methods}

News data collected from BIGKinds in this study were analyzed using NetMiner version 4.4.1. (Cyram Inc., Seongnam, Korea). NetMiner is a specialized network analysis software developed by Cyram reflecting analytical demands of big data and configures data analysis by applying various methods such as statistics, social network analysis, data mining, mechanical learning, etc. [8].

Next, data extracted using NetMiner was subject to a refining process to extract only keywords with a Term Frequency-

Table 1. Topic modeling results

\begin{tabular}{|c|c|c|c|c|c|c|c|}
\hline Item & Article & Probability & \multicolumn{5}{|c|}{ Core keyword (probability distribution) } \\
\hline Vaccination & 169 & 24.56 & $\begin{array}{c}\text { Vaccination } \\
\begin{array}{c}(0.032) \\
\text { Level } \\
(0.007)\end{array}\end{array}$ & $\begin{array}{l}\text { Vaccine } \\
(0.025) \\
\text { Children } \\
(0.006)\end{array}$ & $\begin{array}{l}\text { Infectious disease } \\
\qquad \begin{array}{c}(0.009) \\
\text { Sickbeds } \\
(0.006)\end{array}\end{array}$ & $\begin{array}{c}\text { Nurse } \\
(0.008) \\
\text { Committee } \\
(0.006)\end{array}$ & $\begin{array}{l}\text { Recuperation } \\
\begin{array}{c}(0.007) \\
\text { Elderly } \\
(0.006)\end{array}\end{array}$ \\
\hline $\begin{array}{l}\text { Dental health } \\
\text { care }\end{array}$ & 153 & 22.24 & $\begin{array}{l}\text { Teeth } \\
(0.017) \\
\text { Class } \\
(0.007)\end{array}$ & $\begin{array}{c}\text { Gums } \\
(0.008) \\
\text { Director } \\
(0.006)\end{array}$ & $\begin{array}{l}\text { Disinfection } \\
(0.008) \\
\text { Donation } \\
(0.006)\end{array}$ & $\begin{array}{c}\text { Love } \\
(0.007) \\
\text { Thanks } \\
(0.006)\end{array}$ & $\begin{array}{c}\text { Event } \\
(0.007) \\
\text { Examination } \\
(0.005)\end{array}$ \\
\hline Medical industry & 138 & 20.06 & $\begin{array}{c}\text { Enterprise } \\
(0.023) \\
\text { Investment } \\
(0.008)\end{array}$ & $\begin{array}{l}\text { Industry } \\
(0.019) \\
\text { Products } \\
(0.008)\end{array}$ & $\begin{array}{c}\text { Implant } \\
(0.013) \\
\text { Devices } \\
(0.007)\end{array}$ & $\begin{array}{c}\text { Revenue } \\
(0.010) \\
\text { Disinfection } \\
(0.007)\end{array}$ & $\begin{array}{l}\text { Insurance } \\
(0.008) \\
\text { Sales } \\
(0.007)\end{array}$ \\
\hline $\begin{array}{l}\text { Era of confusion } \\
\text { during the } \\
\text { COVID-19 }\end{array}$ & 120 & 17.44 & $\begin{array}{l}\text { Spread } \\
(0.007) \\
\text { Italy } \\
(0.005)\end{array}$ & $\begin{array}{c}\text { Production } \\
(0.006) \\
\text { Respiratory system } \\
(0.004)\end{array}$ & $\begin{array}{c}\text { Price } \\
(0.05) \\
\text { Broadcast } \\
(0.004)\end{array}$ & $\begin{array}{l}\text { Words } \\
(0.005) \\
\text { Worry } \\
(0.004)\end{array}$ & $\begin{array}{l}\text { Telephone } \\
\text { (0.005) } \\
\text { Supply } \\
(0.004)\end{array}$ \\
\hline $\begin{array}{l}\text { Changes in daily } \\
\text { life during the } \\
\text { COVID-19 }\end{array}$ & 108 & 15.70 & $\begin{array}{c}\text { Daegu } \\
(0.028) \\
\text { Busan } \\
(0.008)\end{array}$ & $\begin{array}{c}\text { Gwangju } \\
(0.016) \\
\text { Daejeon } \\
(0.006)\end{array}$ & $\begin{array}{c}\text { Student } \\
(0.010) \\
\text { Association } \\
(0.006)\end{array}$ & $\begin{array}{l}\text { Chairman } \\
(0.009) \\
\text { Medicine } \\
(0.005)\end{array}$ & $\begin{array}{c}\text { City } \\
(0.009) \\
\text { Request } \\
(0.005)\end{array}$ \\
\hline
\end{tabular}


Inverse Document Frequency (TF-IDF) coefficient of 0.5 or higher, and LDA topic modeling was performed to derive the topics.

\section{Results}

In order to analyze issues in the dental sector in the wake of the spread of COVID-19, related news articles were collected with the search words 'corona' and 'dentistry' from BIGKinds in 2020 and the first half of 2021. Words used as formalities and conventionally appearing in most articles were excluded, and only keywords having a weighted average of 0.5 or more were extracted through TF-IDF, which judges the importance of words. Afterwards, LDA topic modeling analysis was performed to derive a total of 5 topics, and the results are as shown in Table 1.

Of the 5 derived topics, the topic that accounted for the biggest portion was 'vaccination', which was followed by 'dental health care', 'medical industry', 'time of confusion during the COVID-19 pandemic', and 'changes in daily life during the COVID-19 pandemic'. Such results can be interpreted as social phenomena that are major issues in the dental sector and social phenomena in which the press and public are interested due to the spread of COVID-19.

In order to see the contents of the topic in detail, $10 \mathrm{key}-$ words allocated to each topic were presented in the order of probability distribution and this was visualized as shown in Figure 1 so that it could be identified at a glance. The lines shown in Figure 1 was made thicker when the allocation rate of words was higher, and the interpretations of the meaning of the 5 extracted topics are as follows.

\section{Vaccination}

Keywords making up the first topic were 'vaccination', 'vaccine', 'infectious disease', 'nurse', 'recuperation', 'level', 'children', 'sickbeds', 'committee', and 'elderly'. Most of the articles were on the huge role of over a thousand public health doctors who were dispatched to the Daegu and Gyeongsangbuk-do Province region in late February 2020 to control the spread of COVID-19, when this region was thrown into a state of panic due to the explosive spread of COVID-19. COVID-19 outbreaks in Gwangju in July 2020, the general strike of doctors amidst the second wave of COVID-19 in August 2020, and articles on the discussions regarding crisis-response plans as COVID-19 became prolonged in December 2020. In January 2021, most of the news articles were on the COVID-19
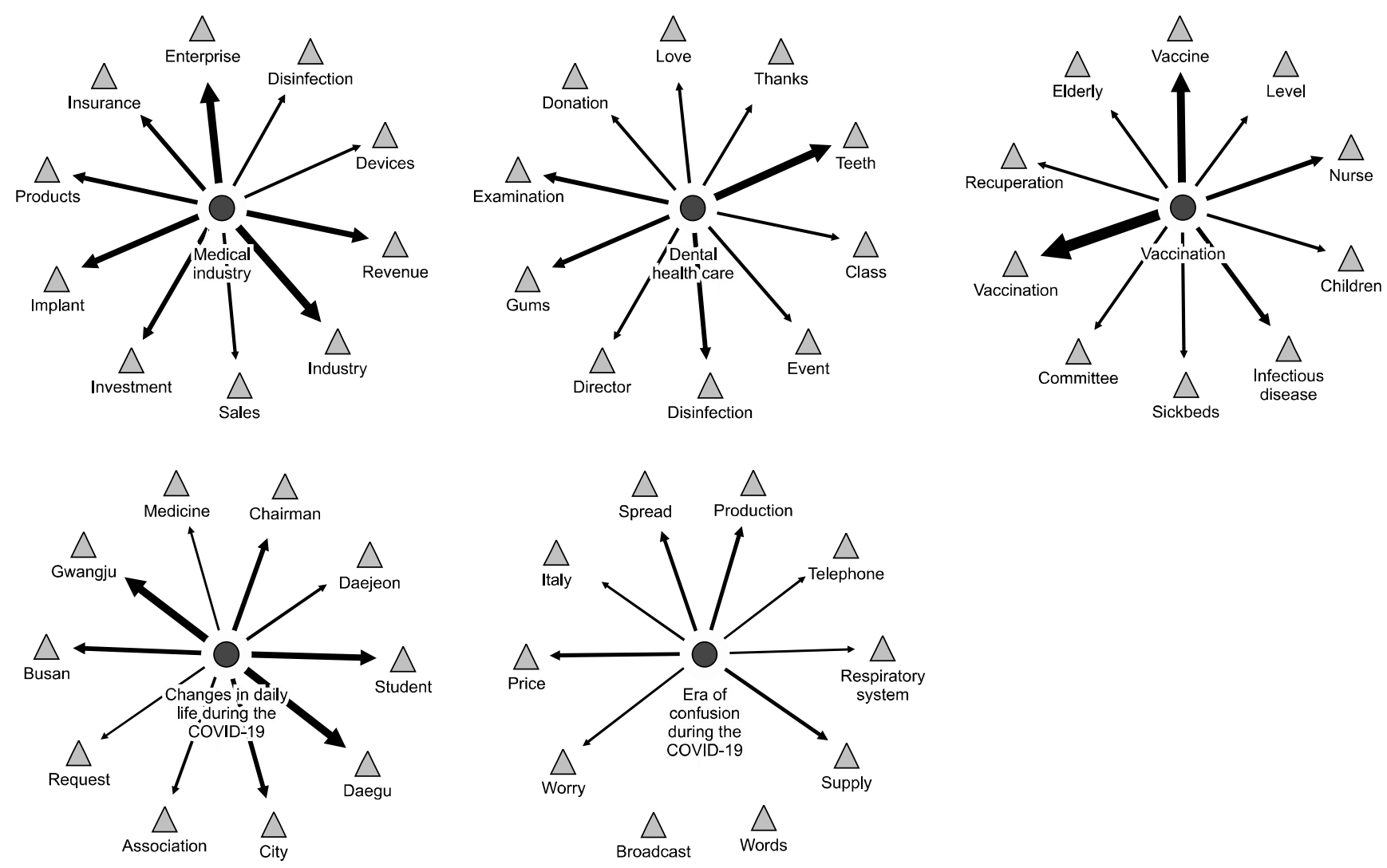

Figure 1. Visualization of topics and words. 
vaccination planning stages and the order of who would receive vaccinations first, and in February 2021, most of the articles were on the announcement by the Centers for Disease Control and Prevention (CDC) of the detailed plans for vaccination, interest and concerns over the vaccine supply, and quarterly vaccination progress.

\section{Dental health care}

Keywords making up the second topic were 'teeth', 'gums', 'disinfection', 'love', 'event', 'class', 'director', 'donation', 'thanks', and 'examination'. Most of the articles from February 2020 were about preventing the immune system from weakening and thorough personal hygiene practices such as washing hands to respond to COVID-19, and about difficulties of the government in procuring masks, complaints about bad breath that people did not perceive before they started wearing masks, and the fact that while the society urged staying in to prevent COVID-19, those who suffered because of dental treatment were going to hospitals to receive treatment regardless of the situation. Other articles included local health centers producing children's videos for oral health education, which is important during kindergarten and elementary school when baby teeth switch to adult teeth, and the attempts to carry out oral health education projects through non-contact methods. There were also articles reporting that there was an increase of patients who recognized the importance of oral health and dental treatment in the COVID-19 pandemic period by brushing teeth more closely.

\section{Medical industry}

Keywords making up the third topic were 'enterprise', 'industry', 'implant', 'revenue', 'insurance', 'investment', 'product', 'devices', 'disinfection', and 'sales'. Most of the articles were about effects in the domestic medical device industry due to COVID-19, and about how small businesses that had to close and reopen repeatedly due to the rapid spread of COVID-19 in 2020 began to go out of business in droves. Meanwhile, articles on the dental industry were mostly about anticipations for growth seen in the unveiling of new business models focusing mainly on the digital dentistry using global dental diagnosis equipment and AI, and the fact that overseas performance records were being broken. Furthermore, there were also many articles stating that 'orthodontic surgery inside the mask' was highly popular due to the continued duration of the COVID-19 pandemic.

\section{Era of confusion during the COVID-19}

Keywords making up the fourth topic were 'spread', 'production', 'price', 'words', ‘telephone', 'Italy', 'respiratory system', 'worry', and 'supply'. As COVID-19 spread nationwide in February 2020, "national safe hospitals" were operated by the government to treat respiratory and non-respiratory patients, to block infections within hospitals. However, there were many articles pointing out that there were no national safe hospitals in Daegu where most COVID-19 patients were located and articles reporting that huge sums of money from health insurance were spent to examine 260,000 cases once examinations over the telephone were recognized to stop the spread of COVID-19. There were also many articles about opposition from the medical sector against the government attempting to expand the quota for medical schools and to newly build a public medical school on the premise that there were severe shortages of medical professionals while the COVID-19 situation became more serious, and articles about how infections were continuously spreading because public health doctors and COVID-19 patients visited multiple locations.

\section{Changes in daily life during the COVID-19}

Keywords making up the fifth topic were 'Daegu', 'Gwangju', 'students', 'chairman', 'city', 'Busan', 'Daejeon', 'association', 'medicine', and 'request'. Most of the articles were about a rapid increase in the export sales of patents that reflected the capacities of K-health and medicine and K-biopharmaceutical products, and the expansion of the K-beauty global digital healthcare market applying K-quarantine. Many articles related to the dental sector were on the implementation of smart healthcare, which elicited a high level of interest, with activities such as dental diagnoses and career experience education using digital dental devices, expanding the supply of oral scanners, and developing dental correction application programs based on AI deep-learning.

\section{Discussion}

While the entire global community suffers from the effects of the COVID-19 pandemic, Research and development is being actively conducted by governments of countries around the world and bio-pharmaceutical companies centered mostly in the US for the development of vaccines and treatments to respond to the pandemic. Vaccines from Pfizer (Pfizer Inc., New York, NY, USA), Moderna (Moderna, Inc., Massachusetts, MA, USA), AstraZeneca (AstraZeneca Co., Cambridge, England), etc. received approval from authorities such as the U.S. Food and Drug Administration (FDA) and European Medicines Agency (EMA), and are being used to vaccinate people. Moreover, various types of vaccines and treatments for COVID-19 are still being developed by pharmaceutical and bio companies around the world in addition to the vac- 
cines and treatments that are currently being used [9]. The spread and prolongation of COVID-19 infections are continuing to spread fear among dentistries related to treatment and examinations, and in relation to economic stagnation as well as controlling COVID-19 [10].

Accordingly, this study analyzed issues in the dental sector caused by the spread of COVID-19 using the topic modeling analysis method, utilizing LDA from domestic news articles based on keyword analysis data applying the topic ranking algorithm of the BIGKinds.

Results of the analysis showed the 5 topics derived to be in the order of 'vaccination', 'dental health care', 'medical industry', 'time of confusion during the COVID-19 pandemic', and 'changes in daily life during the COVID-19 pandemic'. Keywords making up the first topic were 'vaccination', 'vaccine', 'infectious disease', 'nurse', 'recuperation', 'level', 'children', 'sickbeds', 'committee', and 'elderly'. Most of the articles in February 2021 were on the announcement by the $\mathrm{CDC}$ of a detailed plan for vaccination, interest and concerns about the vaccine supply, and quarterly vaccination progress. Therefore, based on such contents, this study named the topic 'vaccination'. Since the first confirmed COVID-19 case was found in Daegu in February 2020, COVID-19 spread nationwide and there was fierce competition between local governments and agencies on who receives the vaccine first as part of the plan to stop the spread of COVID-19. This even led to a situation where priority vaccination was requested from the CDC [11]. COVID-19 vaccinations began in February 2021, starting with medical professionals at hospitals caring for COVID-19 patients, patients and workers at recuperation hospitals and facilities, and first responders to COVID-19 cases. The final goal of vaccination is herd immunity, and the national vaccinate rate is crucial to achieve this. Herd immunity is based on the theory that receiving vaccination to prevent infection not only is for the benefit of the individual, but also for neighbors and the entire society. People were urged to persuade as many people as possible to be vaccinated, which can help stabilize society and enable everyone to participate in becoming immune [12].

In April 2020, the government organized the Pan-government COVID-19 Treatment/Vaccine Development Support Committee to gather the capacities of the government, businesses, universities, research centers, hospitals, and the rest of the private sector, which is providing full support for the prompt development of COVID-19 vaccines manufactured in South Korea [13]. It is hoped that free COVID-19 vaccination will proceed smoothly to allow society to return to normalcy, and there are expectations regarding the development of a COVID-19 vaccine with the goal of becoming commercial- ized by the first half of next year, 2022 .

Keywords composing the second topic were 'teeth', 'gums', 'disinfection', 'love', 'event', 'class', 'director', 'donation', 'thanks', and 'examination'. Since the outbreak of COVID-19 in 2020, it was found that there was a rapid increase of personal hygiene practices for preventing infection and ensuring physical health throughout society. Based on this, this topic was named 'dental health care.' According to the American Association of Endodontists (AAE), recent survey results indicated that a red flag has been raised regarding dental health among Americans because of COVID-19. Furthermore, in a survey conducted by the health policy committee of the American Dental Association (ADA) that was published in September of last year, it was reported that there was a significant increase in oral diseases within the US since the outbreak of COVID-19. The "Press in Press" team of Korea Research investigated dental health care habits since the outbreak of COVID-19 among 1,000 male and female over the age of 18 residing nationwide from February 19 to 22, 2021.

Results showed that 2 out of 3 people actively practiced oral health care $(67 \%)$, but not even half $(47 \%)$ responded that their teeth were healthy. Less than half (47\%) also answered that they received regular dental checkups prior to COVID-19 and $48 \%$ answered that they received dental checkups during the year of 2020. Among the respondents who said the frequency of dental checkups dropped since COVID-19 (16\%), $65 \%$ said that the risk of COVID-19 infection was a factor that affected the decline in frequency. COVID-19 had an impact not only on regular checkups, but also on dental treatment. Half of those who said that they did not receive dental treatment they needed after the outbreak of COVID-19 said the pandemic was the main reason (reasons included the risk of COVID-19 infection (41\%) and reduced frequency of going out $(10 \%)$. There was no significant change in brushing teeth after COVID-19 (no change- $86 \%$ ), but there was a growing trend in efforts for additional care such as increased water consumption (45\%), longer time brushing teeth (27\%), increased use of mouth wash $(26 \%)$, and increased use of interdental toothbrushes and floss $(25 \%)$. While the trend of practicing additional home care is positive, it appears that more assertive efforts are needed for dental care in today's situation where there are many restrictions due to COVID-19 affecting regular examination and dental treatment [14].

Keywords constituting the third topic were 'enterprise', 'industry', 'implant', 'revenue', 'insurance', 'investment', 'product', 'devices', 'disinfection', and 'sales'. Most of the articles on the dental industry were about anticipation for growth by unveiling new business models focusing mainly on digital dentistry using global dental diagnosis equipment and 
$\mathrm{AI}$, and reports that overseas performance records were being broken. This topic was named 'medical industry'.

Osstem Implant's 2021 Q3 (OSSTEM IMPLANT CO., LTD., Seoul, Korea) overseas performance broke the 100 billion KRW quarterly sales milestone for the first time ever. Revenue in China increased by $28.4 \%$ compared to the same period in the previous year, leading its overseas performance, and performance in other regions such as North America and Europe that stagnated due to COVID-19 also started to grow again [15].

Vatech (Vatech Co., Hwaseong, Korea) also announced its highest ever first quarter earnings, posting 75 billion KRW in sales and 13 billion KRW in operating profits in 2021 Q1, representing increases of $37.6 \%$ and $106.3 \%$, respectively, compared to the same period in the previous year. Even when compared to 2019 Q1, which was prior to the outbreak of COVID-19, revenue and operating profits increased by $29.9 \%$ and $44.2 \%$, respectively [16].

As wearing masks became mandatory, there has been a growth in people receiving dental procedures. There has been a growth in people starting orthodontics or plastic surgery as they are able to hide the shape of their mouths by wearing masks. Experts pointed out, "This is a consumption behavior added by a want for compensation over the difficulties of having a normal lifestyle due to social distancing" [17].

In the 'with COVID' period, dental treatment may be deferred for a while, but it cannot be stopped indefinitely. Patients will look to minimize the number of visits to dentistries and find dental clinics that can provide the safest and fastest dental treatment, and dental equipment and technologies will evolve quickly to satisfy this demand.

Keywords included in the fourth topic were 'spread,' 'production,' 'price,' 'words,' 'telephone,' 'Italy,' 'respiratory system,' 'worry,' and 'supply.' As the number of cases increase rapidly, 'nth infections' are now occurring within regions. Therefore, this topic was named the 'Era of Confusion During the COVID-19 Pandemic.' On August 11, 2020 (local time) the WHO recommended people to "delay non-urgent medical treatment until COVID-19 slows down" due to concerns of dental workers being infected by COVID-19 in different countries. This measure by the WHO appears to be based on concerns of higher infection risks caused by aerosols during dental treatment [18].

COVID-19 vaccination is rapidly increasing around the world, and this also applies for South Korea. It is too early to discuss the end of the COVID-19 pandemic yet. Under such circumstances, there are growing inquiries to dental clinics on whether it is safe to receive dental treatment and how dental treatment will be provided. Even before COVID-19, hospitals and dental clinics placed great importance on disinfection and sterilization. This is because they are very knowledgeable about the risk of spreading viruses and infections [19].

In this global COVID-19 pandemic, dental treatment must be performed with thorough infection preventive procedures, for the benefit of both patients and dental workers. If medical professionals have any COVID-19 symptoms, they should self-quarantine until receiving test results, and in such cases, their agencies should accept this as advisable and ensure that those on quarantine receive no disadvantages. Medical staff should be required to wash their hands before and after treatment, and social distancing of 2 meters should be maintained between patients and other patients, and complete partitions or quarantined rooms are recommended to prevent the spread of aerosol. It is also strongly recommended to wear KF94 masks and full-body disposable gowns. Whenever possible, disposable dental equipment should be used and disinfection is mandatory [10].

Keywords constituting the fifth topic were 'Daegu', 'Gwangju', 'students', 'chairman', 'city', 'Busan', 'Daejeon', 'association', 'medicine', and 'request'. It was found that the majority of articles were on remote classes, contact-free interviews, and domestic medical equipment industry trends due to COVID-19. Therefore, this topic was named 'daily life during the COVID-19'. Most of the articles were about the rapid increase of export sales of patents based on the accumulated capabilities in K-health and medicine and K-biopharmaceutical products, and the expansion of the K-beauty global digital healthcare market using K-quarantine. Diagnosis kits manufactured in South Korea performed a significant role in slowing COVID-19 infections. The South Korean diagnosis kit company A developed diagnosis kits, which led K-quarantine from early on following the outbreak of COVID-19 and this company has been exporting the kits globally. It is also possible to purchase a COVID-19 self-test kit at drug stores to check whether you are asymptomatic. Diagnostic technologies that test for COVID-19 are evolving according to the situations of the times, and this is leading to continuous patent applications [20]. Therefore, it is anticipated that it will be possible to overcome the pandemic with the application of the unique South Korean quarantine system and medical industry technologies that outperform the health and medical systems of advanced countries. It is expected that patent applications will be made for various diagnostic technologies responding to the needs of the times, and it has been announced that the development of relevant technologies will be actively supported through quick and accurate reviews.

This study analyzed issues in the dental sector using topic modeling to identify dental trends during the COVID-19 pan- 
demic from a macroscopic perspective. However, because this study dealt mainly with dental issues in South Korea, there remain limitations on generalizing from its conclusions. There is a need for future studies to continue multi-faceted research on changes and responses in the dental sector due to COVID-19 in both South Korea and abroad.

\section{Conclusion}

This study collected news articles related to the search words 'corona' and 'dentistry' in BIGKinds from 2020 to the first half of 2021 to analyze the issues of the dental sector because of the spread of COVID-19. Five topics were deduced through the topic modeling-LDA method using NetMiner to investigate the contents.

1. The 'vaccination' topic, the main issues were the CDC's announcement on detailed plans for vaccination, interest and concerns on vaccine supplies, and quarterly vaccination progress, etc.

2. The 'dental health care' topic, the main issues were personal hygiene to prevent infections after the outbreak of COVID-19 and the rapid increase in interest on physical health throughout society.

3. The 'medical industry' topic, the main issues were the dental sector unveiling new business models having anticipations for growth while renewing overseas performance records.

4. The topic titled 'time of confusion during the COVID-19', the main issues were the rapid increase of confirmed cases and 'nth infections' occurring within respective areas, and concerns of infection during dental treatment.

5. The topic named 'changes in daily life during the COVID-19', the main issues were remote classes and contact-free interviews resulting from the COVID-19 pandemic.

The biggest issued in the dental sector in 2020 and the first half of 2021 due to the spread of COVID-19 were found to be 'vaccination', 'dental health care', 'medical industry', 'time of confusion during the COVID-19', and 'changes in daily life during the COVID-19'. In the future, research should be conducted on understanding the changes of the dental sector and on plans for systematically resolving such issues.

\section{Conflict of Interest}

No potential conflict of interest relevant to this article was reported.

\section{ORCID}

Kyung-Hui Moon, https://orcid.org/0000-0002-4584-4237

\section{References}

1. Korea Disease Control and Prevention Agency [Internet]. Cheongju: Korea Disease Control and Prevention Agency [cited 2021 Aug 10]. Available from: http://www.kdca.go.kr.

2. Corona virus disease 19 (COVID-19) [Internet]. Cheongju: Korea Disease Control and Prevention Agency [cited 2021 Aug 10]. Available from: https://terms.naver.com/entry.naver?docId= $5912275 \&$ cid $=43667 \&$ categoryId $=43667$.

3. COVID-19 pandemic [Internet]. Wikipedia [cited 2021 Aug 10]. Available from: https://ko.wikipedia.org/wiki/COVID-19 pandemic.

4. Wu YA, Hsieh SK. Public opinion toward CSSTA: a text mining approach. Comput Linguist Chin Lang Process 2014;19:19-28.

5. Lee SS. Network analysis methods applications and limitations. Seoul: Cheongram; 2018.

6. Choi HJ. Analysis of Korean contemporary dance research trends using text mining. Korean J Arts Educ 2019;17:103-18.

7. Shim JH. Authorities are on emergency alert for unknown pneumonia ahead of the "Chunjeol Great Movement" in China [Internet]. Seoul: Yonhapnews [cited 2021 Jul 20]. Available from: https://www.yna.co.kr/view/AKR20200106110800083?input $=1195 \mathrm{~m}$.

8. Cyram. Text network analysis service [Internet]. Seongnam: Cyram [cited 2021 Aug 10]. Available from: http://www.cyram. com/solution/solution 01 03.jsp.

9. Korea Health Industry Development Institute [Internet]. Cheongju: KHIDI [cited 2021 Aug 10]. Available from: https://www.khidi.or.kr/kps.

10. Kim J. Guidelines for dental clinic infection prevention during COVID-19 pandemic. J Korean Acad Dent Adm 2020;8:1-7.

11. Han YH. Before we even have a vaccination plan...The agencies that requested "we first." [Internet]. Seoul: JoongAng Ilbo [cited $2021 \mathrm{Jul}$ 20]. Available from: https://news.joins.com/article/ olink/23563897.

12. Coronavirus infection-19/Vaccine/South Korea [Internet]. Seoul: namu.wiki [cited 2021 Jul 20]. Available from: https://namu.wiki/w/Coronavirus20infection-19/Vaccine/Sou th20Korea.

13. Central Disaster and Safety Countermeasures Headquarters [Internet]. Sejong: MOHW [cited 2021 Aug 20]. Available from: www.mohw.go.kr.

14. Hankook Research. "I'm afraid of getting Corona" I should have gone to the dentist, but I couldn't [Internet]. Seoul: Hankook Research [cited $2021 \mathrm{Jul}$ 20]. Available from: https://www. hankookilbo.com/News/Read/A2021032215010005334.

15. Kim YK. 'Corona cannot be stopped' Osstem Implant breaks overseas performance again [Internet]. Seoul: MONEYTODAY [cited $2021 \mathrm{Jul}$ 20]. Available from: https://m.news.nate.com/ view/20201103n05551. 
16. Kim SW. Vatech, record high performance in $1 \mathrm{Q}$... Operating profit of 13 billion won, up 103\% from the previous year [Internet]. Seoul: Sedaily [cited $2021 \mathrm{Jul} 20$ ]. Available from: https://www.sedaily.com/NewsVIew/22MBIUR0F7.

17. Huh YJ. "Because I'm wearing a mask...” Plastic surgery and orthodontics boom [Internet]. Seoul: ChosunMedia [cited 2021 Jul 20]. Available from: https://www.chosun.com/national/national_general/ 2021/01/04/CHZAJ7OTYVDARJUBPMABHJMF7M/.

18. Kim YW. WHO "Recommends postponement of dental treat- ment due to concerns about aerosol infection" [Internet]. Seoul: dongA.com [cited 2021 Jul 20]. Available from: https://www. donga.com/news/Inter/article/all/20200812/102416179/1.

19. Jeon BS. Dental treatment that requires taking off a mask, is corona infection okay? [Internet]. Seoul: KUKMINILBO [cited 2021 Jul 20]. Available from: http://news.kmib.co.kr/article/view.asp? arcid $=0015921222 \& \operatorname{code}=61221111 \& \operatorname{sid} 1=$ all .

20. Korean Intellectual Property Office [Internet]. Daejeon: KIPO [cited 2021 Aug 10]. Available from: https://www.kipo.go.kr/. 